SPACE

Meteors and Meteorology

from a Correspondent

COSPAR, the Committee on Space Research, held its first meeting in the Soviet Union last month. Delegates met in Leningrad at the invitation of the USSR Academy of Scicnces. The proceedings were not taken up cntirely by preliminary reports and theories on the lunar surface experiments, although these were much in evidence.

Dr F. Möller (Metcorological Institute, Munich), reviewing recent developments in space meteorology, said that the Nimbus III satellite with on-board multichannel infrared spectrometers has made it possible to measure the vertical temperature distribution of the atmosphere between 0 and $30 \mathrm{~km}$ to an accuracy of about $1.5^{\circ} \mathrm{C}$. These data are being used successfully in routine weather forecasting. Ozone profiles for clear and cloudy areas of th $\geqslant$ globe can be computed with less than 10 per cent error. Ozone seems to be a very good tracer of motions in the lower stratosphere. The usefulness of measurements of surface temperature, emissivity and reflectivity in weather forecasting was stressed by many speakers. Increased accuracy in the measurement of vertical profiles in the atmosphere and ionosphere and their variation with time and solar activity will make the new COSPAR International Reference Atmosphere to be published in 1970 very welcome.

Discussing the near Earth meteoroid environment, Dr J. A. MeDonnell (University of Kent) showed that data from the microphone and penetration experiments detecting dust particles in space were beginning to agree at last. This seems to have brought about the final demise of the "Earth dust cloud". The concentration of meteoroids in the vicinity of the Earth and the Moon does not seem to differ considerably from that of dust particles in interplanetary spacc. An interesting controversy arose as to whether meteor streams contain any particles of mass $10^{-7}$ to $10^{-11} \mathrm{~g}$. Dr W. M. Alexander and co-workers (Baylor University, Texas) found significant variation in the detected flux, during periods of major meteor showers, from Lunar Explorer 35 and OGO III data. On the other hand, Dr E. P. Mazets (Academy of Sciences, USSR), using data from the Cosmos 135 and Cosmos 163 satellites, found that "extensive measurements covering eight major showers failed to reveal a correlation between the impact rate and meteor shower activity". The suspension time of retarded meteoroid particles in the upper atmosphere is very uncertain. A factor of $10^{4}$ was mentioned by Drs C. L. Hemenway and D. S. Hallgreen (State University of New York at Albany). This uncertainty is carried over into flux estimations made from collections of dust by sounding rockets.

\section{CONTINENTAL DRIFT}

\section{Anomaly Correlutions}

\section{from our Geomagnetism Correspondent}

THe theory of continental drift has come a long way since Francis Bacon first noticed the congruency between the west coast of Africa and the east coast of South America in the seventeenth century; yet these two coastal areas continue to provide fresh evidence for the theory. Recently Bacon's notion has been strikingly confirmed by a sophisticated computer fit of the coasts at the 500 fathom line, similar age boundaries have been shown to exist on the adjacent parts of both continents, similar geosynclinal features have been found in both Brazil and Gabon, and common features in anorthosite distribution have been demonstrated.

Detailed geological mapping is, of course, an obvious way of looking for similarities between the continental coast, but such surveys are frequently hampered by jungle cover, especially in Africa. The next best thing is airborne magnetic surveying which is essentially a form of remote geological mapping. Strangway and Vogt (Earth Plan. Sci. Lett., r, 429; 1970) have thus collected together and compared all known aeromagnetic data over the coastal regions in question. As a result, a new correlation must now be added in support of an Africa and South America once joined. together.

Aeromagnetic surveys available include Sierra Leone, Ghana, Nigeria and the Ivory Coast in Africa and Surinam and Guyana in South America. What emerges from the analysis of these data by Strangway and Vogt is a boundary in both continents between two distinct types of magnetic anomaly. The south-western area of the Ivory Coast is characterized by a series of broadly parallel NE-SW trending anomaly bands with typical wavelengths of $30 \mathrm{~km}$ and total amplitudes of $500-$ 800 gamma. There is no obvious correlation between these anomalies and the known surface geology which suggests that the pattern is due to a fundamental characteristic of the granitic Pre-Cambrian basement. Similar, though less pronounced, banding is also seen in Sierra Leone. In Ghana, on the other hand, these bands are absent and the magnetic map comprises "rather nondescript" regional variations. By implication, therefcre, there must be some rathcr basic difference between the Sierra Leone/Ivory Coast and Ghana basements with the boundary running northward through the central Ivory Coast.

Turning to South America, Surinam and Guyana are again characterized by NE-SW band anomalies of similar wavelengths and amplitudes to those in Africa. Because no other anomaly data were available from South America, Strangway and Vogt earried out further surveys of their own over the shield region of NorthEast Brazil. Here the NE-SW bands were absent. The boundary between the banded and non-banded anomalies in South America runs along the southern end of the Amazon Basin.

When Africa and South America are reconstructed in what is thought to be their pre-drift positions the magnetic boundaries in each continent match. Furthermore, there is a second major boundary of a similar nature in South America striking about $\mathrm{N} 45^{\circ} \mathrm{E}$ through Recife. There is a distinct possibility that this boundary also crosses into Africa although unfortunately there are no acromagnetic data to confirm it. A surprising feature of the magnetic boundaries, however, is that they do not coincide with any of the age boundaries, or vice versa. Nevertheless, the new magnetic boundaries stand as important correlators in their own right even though their precise origin is still not fully understood. 